\title{
COLECISTECTOMIA: ASPECTOS TÉCNICOS E INDICAÇÕES PARA O TRATAMENTO DA LITÍASE BILIAR E DAS NEOPLASIAS
}

\author{
CHOLECYSTECTOMY: TECHNICALASPECTS AND INDICATIONS FOR \\ THE TREATMENT OF BILIARY CALCULI AND NEOPLASMS
}

José Sebastião dos Santos ${ }^{1}$, Ajith Kumar Sankarankutty', Wilson Salgado Júnior ${ }^{1}$, Rafael kemp², José Luís Pimenta Módena ${ }^{1}$, Jorge Elias Júnior ${ }^{3}$, Orlando de Castro e Silva Júnior ${ }^{1}$

\begin{abstract}
'Docentes, ${ }^{2}$ Médico Assistente e Pós Graduando. Divisão de Cirurgia Digestiva do Departamento de Cirurgia e Anatomia. ${ }^{3}$ Docente, Divisão de Ciência das Imagens e Física Médica do Departamento de Clínica Médica. Faculdade de Medicina de Ribeirão Preto - USP. CorRespondência: José Sebastião dos Santos. Divisão de Cirurgia Digestiva do Departamento de Cirurgia e Anatomia da FMRP-USP. Av. Bandeirantes, 3900, 14049-900 - Ribeirão Preto / SP. (email: jsdsanto @ fmrp.usp.br)
\end{abstract}

Santos JS, Sankarankutty AK, Salgado Júnior W, kemp R, Módena JLP, Elias Júnior J, Castro e Silva Júnior O. Colecistectomia: aspectos técnicos e indicações para o tratamento da litíase biliar e das neoplasias. Medicina (Ribeirão Preto) 2008; 41 (4): 449-64.

RESUMO: A remoção cirúrgica da vesícula biliar é uma operação realizada há mais de um século e nos últimos 25 anos foi objeto de inovação nos seus fundamentos técnicos, especialmente, em relação ao acesso e a exploração da via biliar principal. As indicações mais freqüentes de colecistectomia são a litíase biliar e suas complicações (colecistite aguda, coledocolitíase, colangite, pancreatite aguda biliar) e o câncer da vesícula biliar. Inicialmente, as colecistectomias para tratamento da litíase biliar eram realizadas por meio de laparotomia. No fim do século vinte, a colecistectomia passou a ser feita por meio de acessos menores como a minilaparotomia e em seguida pela videolaparoscopia, que é o acesso considerado como padrão na atualidade. Mais recentemente, a colecistectomia tem sido realizada, em caráter experimental ou excepcional, por meio do acesso transgástrico e transvaginal. Os benefícios do acesso videolaparoscópico são incontestáveis, mas o emprego desse acesso requer cautela e capacitação para minimizar a incidência de lesões traumáticas da via biliar e de outras estruturas.

Descritores: Colecistectomia. Litíase. Doenças Biliares. Colelitíase. Colecistite Aguda. Coledocolitíase. Pancreatite. Doença Aguda. Neoplasias da Vesícula Biliar.

\section{1- INTRODUÇÃO}

A remoção cirúrgica da vesícula biliar (colecistectomia) é uma operação que começou ser realizada no fim do século dezenove. Os seus fundamentos desenvolveram-se no século vinte. Nos últimos 25 anos, os seus princípios técnicos, especialmente, em relação ao acesso foram objeto de grandes inovações. A colecistectomia está indicada no tratamento da litíase biliar e suas complicações e nas neoplasias da vesícula biliar. Inicialmente, as colecistectomias para tratamento da litíase biliar eram realizadas por meio de laparotomia. No fim do século vinte a colecistectomia passou a ser feita por meio de acessos menores como a minilaparotomia e em seguida pela videolaparoscopia, que é o acesso considerado como padrão na atualidade. Mais recentemente, a colecistectomia tem sido realizada, em caráter experimental ou excepcional, por meio do acesso transgástrico e transvaginal. ${ }^{1,2}$ Dessa forma, em que pese as controvérsias, a colecistectomia é uma operação passível de ser executada através do acesso aos orifícios naturais do organismo com auxílio da videoendoscopia e da trasiluminação, habitualmente chamada de NOTES, as iniciais das palavras "natural orifice transluminal endoscopic surgery" 


\section{2- INDICAÇÕES DA COLECISTECTOMIA}

\section{1- Litíse vesicular e suas complicações}

A prevalência de cálculos biliares, nos adultos, estimada mediante estudos epidemiológicos de necrópsia e de investigação clínica varia de 15 a $20 \%$. A litíase vesicular é rara na criança, começa a ser identificada na adolescência, apresenta um marcado acréscimo na incidência entre os 35 e 55 anos e aumenta, gradualmente, a partir dos 55 anos. Estimativas baseadas em estudo de necropsia indicam que, aproximadamente, $50 \%$ dos pacientes idosos têm colelitíase aos 75 anos de idade. A incidência da litíase biliar é maior nas mulheres com múltiplas gestações e está, discretamente, aumentada em pacientes obesos. ${ }^{3}$

Os cálculos biliares humanos são classificados química e morfologicamente em duas categorias: cálculos de colesterol (amarelo-esbranquiçados) puros ou mistos e cálculos pigmentares (pretos e marrons) (Figura 1); os últimos perfazem apenas 10\% dos cálculos vesiculares. Os defeitos metabólicos e da secreção de lipídios biliares, a disfunção da vesícula biliar e a precipitação de colesterol e sais de cálcio são fatores envolvidos na formação dos cálculos biliares. O aumento da síntese de colesterol ocorre nos obesos, nas usuárias de anticoncepcionais orais, na gravidez, no envelhecimento, na diabetes melito, e na perda ponderal acentuada. ${ }^{3,4}$

A hiposecreção de sais biliares que ocorre na cirrose biliar e na colongite esclerosante e a perda anormal observada na resseção ileal ou outras síndromes de má absorção associadas ou não à hipersecreção de colesterol também são fatores envolvidos na for- mação dos cálculos. Estas alterações levam a supersaturação de colesterol na bile com formação do núcleo de cristais na vesícula biliar. Os cristais crescem e unem se uns aos outros e com outros componentes da bile como a mucina, bilirrubina e o cálcio formando os cálculos. ${ }^{3,4}$

As hipóteses aventadas para formação dos cálculos pigmentares incluem a concentração excessiva de bilirrubina não conjugada insolúvel, a deficiência relativa da concentração de sais biliares para solubilizála, além de outros fatores como o possível excesso de cálcio e mucina na vesícula e a disfunção vesicular. Há associações clínicas bem estabelecidas ou fatores de risco para a litíase vesicular por cálculos pigmentares. As mais importantes são a hemólise crônica como a doença falciforme, a talassemia, a esferocitose hereditária, o uso de prótese de válvula cardíaca, a cirrose avançada, a infestação biliar por parasitas e a infecção biliar bacteriana. ${ }^{3,4}$

$\mathrm{Na}$ história natural da litíase biliar, 40 a $60 \%$ dos portadores de colelitíase são assintomáticos. ${ }^{5} \mathrm{~A}$ incidência do desenvolvimento de sintomas varia de 10 a $30 \%$, durante um seguimento de 2 a 15 anos. $^{5}$ Dos pacientes que se tornam sintomáticos e, portanto com indicação para colecistectomia, 60 a $70 \%$ se apresentam sob a forma de colecistite calculosa; nesse grupo, os sintomas são moderados e de interpretação difícil em $20 \%$ dos casos. A colecistite aguda ocorre, aproximadamente, em $20 \%$ dos casos, e cerca de $10 \%$ apresentam outras complicações da colelitíase, como icterícia, colangite e pancreatite. ${ }^{3}$ A incidência dessas complicações aumenta nos pacientes idosos, onde coexistem outras afecções como diabetes, disfunções cardiorespiratórias e renais.

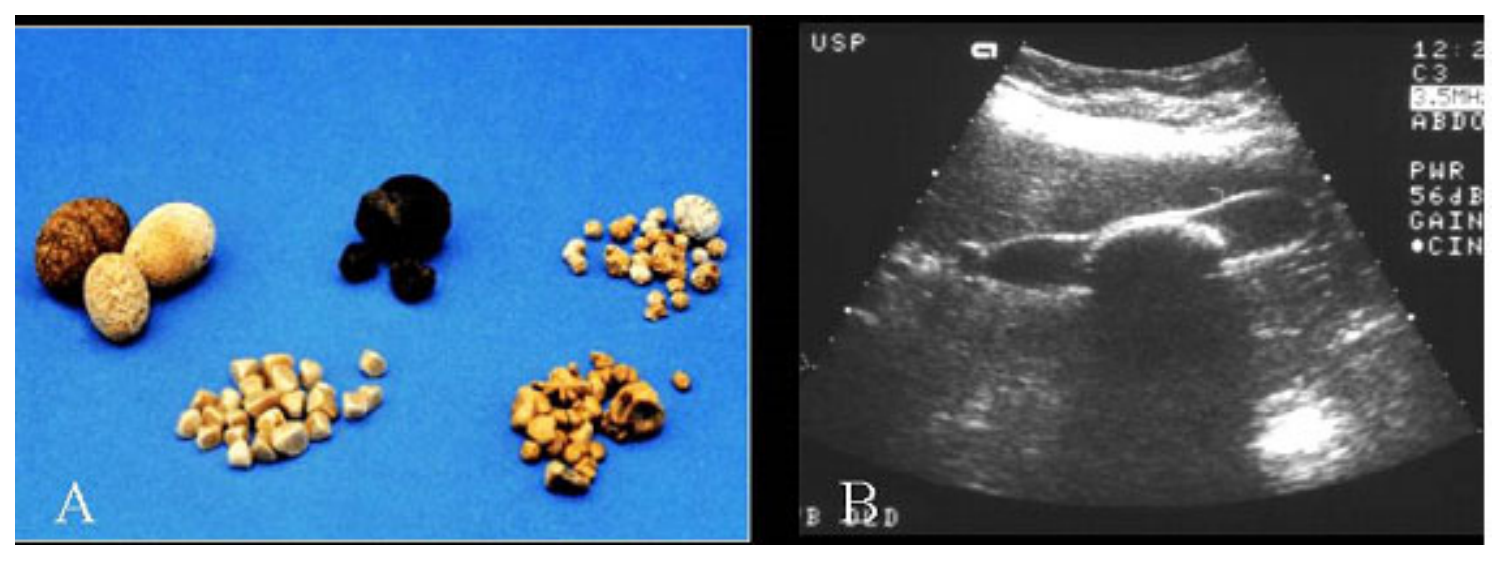

Figura 1: Tipos de cálculos encontrados na colelitíse ${ }^{4}(A)$ e imagem de cálculo grande com sombra acústica observada no exame de ultrassom abdominal. 


\subsection{1- Colelitíase}

A dor biliar é a principal queixa na maioria dos pacientes sintomáticos com cálculos biliares. Embora os pacientes com litíase biliar sintomática, geralmente sejam considerados como portadores de "colecistite crônica", esta não é uma designação completamente precisa porque a formação de cálculos biliares precede a inflamação.

A dor biliar é visceral, localiza-se no epigástrio ou hipocôndrio direito, com frequiência, irradia-se para o ombro direito e a escápula e resulta da obstrução transitória do canal cístico pelos cálculos, seguida de espasmo. A dor pode ser precipitada por uma refeição, porém, mais comumente, não há evento estimulante e a dor pode começar até mesmo à noite. A dor biliar é constante, e não intermitente, assim o termo "cólica" é inadequado. Uma crise típica consiste em dor que aumenta durante 15 minutos a 1 hora, que permanece em um platô durante 1 hora ou mais e, depois, diminui lentamente. Em um terço dos pacientes, a dor tem início súbito e, menos frequientemente, o alívio também é súbito. A dor que dura mais de 5 a 6 horas deve sugerir colecistite aguda ${ }^{6,7}$.

Em ordem decrescente de freqüência, a dor é mais observada no epigástrio, no hipocôndrio direito, no hipocôndrio esquerdo e em várias partes do precórdio ou da porção inferior do abdome ${ }^{8}$. É incorreto considerar a dor localizada em outro local, além do quadrante superior direito, como "atípica" da litíase biliar. A dor irradia-se para outras partes do abdome ou para o dorso em mais da metade dos pacientes, quase sempre para a escápula, porção média do dorso ou extremidade do ombro direito. A crise está associada a vômitos e sudorese na maioria dos pacientes, e o vômito geralmente produz certo alívio. Como nos outros tipos de dor visceral, o paciente com dor biliar geralmente se apresenta inquieto e ativo durante uma crise.

O intervalo entre as crises pode ser de semanas, meses ou anos, e a imprevisibilidade de sua duração é uma característica da doença. A atividade da doença tende a se manter com as mesmas características durante longos períodos. O exame físico geralmente é normal, mas alguns pacientes apresentam dor no epigástrio e no hipocôndrio direito durante uma crise de dor biliar ${ }^{6,7}$.

A distensão crônica da vesícula biliar pode ser causada pela obstrução crônica do canal cístico. A vesícula biliar nesta condição contém um líquido mucóide claro não infectado (vesícula hidrópica). Os pacientes com vesícula hidrópica podem ou não apresentar sintomas.

Aproximadamente $15 \%$ dos cálculos biliares contêm cálcio suficiente para serem observados em radiografias simples do abdome, mas, sem estudos adicionais, não é possível ter certeza de que os cálculos estão realmente dentro da vesícula biliar. Os principais métodos para visualização dos cálculos biliares são a ultra-sonografia (Figura 1) e o colecistograma oral. A especificidade e a sensibilidade de ambos os exames são muito altas, superando 95\%. Embora a ultra-sonografia seja o primeiro exame a ser solicitado, o colecistograma oral não deve ser considerado um exame obsoleto. Se os resultados da ultrassonografia forem negativos e a litíase ainda for considerada uma possibilidade, deve ser realizado um colecistograma oral. Se tanto a ultra-sonografia abdominal quanto o colecistograma oral forem normais e os sintomas forem altamente sugestivos, a ultra-sonografia endoscópica é uma opção para concluir a investigação.

A colecistectomia é o único tratamento definitivo para a colelitíase e é indicada para a maioria dos pacientes sintomáticos. A colecistectomia não é indicada como operação profilática para pacientes assintomáticos. Por outro lado, em função da prevalência elevada da colelitíase em algumas regiões e da história natural relativamente silenciosa da colelitíase assintomática, a indicação da colecistectomia, nesta circunstância, é recomendada de forma seletiva: ${ }^{9}$

\section{Recomendações Fortes}

- Suspeita ou risco de malignidade (cálculos associados com pólipo $\geq 1 \mathrm{~cm}$, vesícula escleroatrófica, cálculo $\geq 3 \mathrm{~cm}$ de diâmetro);

- Colelitíase assintomática em pacientes com coledocolitíase;

- Doença hemolítica crônica;

- Candidatos a transplante de órgãos.

\section{Recomendações Relativas}

- Risco aumentado de evolução para colelitíase sintomática: expectativa de vida maior que 20 anos, pacientes portadores de cálculos $>1,5 \mathrm{~cm}$ ( risco de colecistite aguda) e cálculos pequenos, menores que $0,3 \mathrm{~cm}$, e numerosos em função dos riscos de coledocolitíase e pancreatite biliar;

- Vesícula não funcionante;

- Pacientes com sintomas dispépticos vagos. 


\section{Recomendações Questionáneis}

- Pacientes que serão submetidos à cirurgia na cavidade abdominal;

- Pacientes que têm dificuldade para o acesso aos Serviços de Saúde.

A dor biliar é um evento que cede sem seqüelas, na maioria das vezes, com o tratamento sintomático Por outro lado, trata-se de um evento que identifica os pacientes que podem apresentar complicações da litíase biliar: colecistite aguda, coledocolitíse, colangite e pancreatite aguda. ${ }^{7}$ Assim os pacientes portadores de dor biliar devem ser preparados para a colecistectomia. As vantagens da cirurgia por videolaparoscopia e os progressos da anestesiologia para procedimentos ambulatoriais, associada ao preparo educacional dos pacientes e dos profissionais de saúde, têm possibilitado o tratamento dos pacientes com colelitíase sintomática em regime de cirurgia ambulatorial. ${ }^{10,11}$

\subsection{2- Colecistite aguda}

A colecistite aguda pode resultar da estase biliar, da infecção ou da isquemia da vesícula. Na maioria dos casos (90\%), há obstrução do ducto cístico por cálculo. O processo inflamatório, inicialmente, é de natureza química e há indícios de que concentrações elevadas de sais biliares, colesterol e lisolecitina iniciem esse processo. A estase aumenta a pressão vesicular e impede o fluxo sangüíneo e linfático, propiciando $o$ aparecimento de isquemia. ${ }^{12}$

A infecção é provavelmente um evento secundário. A inflamação, a estase, e a isquemia favorecem a proliferação bacteriana. A cultura da bile é positiva em 50\% dos casos sem perfuração da vesícula e, em $80 \%$, nas gangrenas vesiculares. A incidência de cultura positiva aumenta em função da idade, especialmente após os 60 anos. Os germes mais freqüentes encontrados são entéricos aeróbios e anaeróbios; os aeróbios mais observados são a Escherichia Coli, Klebisiela, Proteus e Streptococcus fecalis. Os anaeróbios freqüentes são Peptostreptococus, Cloristridium perfingens e Bacterióides fragilis. Uma incidência alta de complicações pós-operatórias, sobretudo infecciosas, é observada em pacientes com cultura biliar para bactérias patogênicas. ${ }^{13}$ Em cerca de $10 \%$ dos casos, a infecção pode evoluir para empiema de vesícula com grangrena enfisematosa, em virtude da presença de anaeróbios. Os pontos de necrose da parede vesicular podem perfurar, causando abscessos perivesiculares ou peritonite.
A colecistite aguda acalculosa que representa 2 a $10 \%$ de todos os casos de colecistite aguda; ocorrem mais frequientemente em pacientes que estão gravemente enfermos, com traumatismos, queimaduras sepse, neoplasias e diabetes. O emprego da nutrição parental total em pacientes hipotensos que necessitam múltiplas transfusões de sangue, suporte ventilatório e que estão sépticos reúne condições favoráveis ao desenvolvimento da colecistite aguda acalculosa. ${ }^{14}$ A patogênese não é totalmente compreendida, mas provavelmente envolve alguma condição de estase biliar com aumento da concentração biliar, isquemia por hipoperfusão, agravada com a hipotensão e a vasoconstrição simpática, lesão da mucosa, obstrução funcional e invasão bacteriana.

Nos primeiros dias da crise biliar, a parede da vesícula está hiperemiada, edemaciada e pode apresentar pontos de necrose. A vesícula está distendida pelo conteúdo biliar e com a reabsorção dos sais biliares aparece exsudato inflamatório ou raramente pus ou sangue. Após o término da crise, a mucosa cicatriza e a parede torna-se fibrosada.

A crise típica começa com dor abdominal aguda, contínua, geralmente em pacientes que já apresentam dor biliar; o ataque na maioria dos casos é noturno, entre 23 e 2 horas, o que, talvez possa ser atribuído, à migração dos cálculos para o infundículo facilitada pelo decúbito dorsal. ${ }^{15}$ A obstrução da vesícula e o processo inflamatório que envolve o peritônio parietal e visceral são as causas da dor. Inicialmente, a dor é mal localizada, antes de se deslocar para o quadrante superior direito e tornar-se mais intensa e associada à palpação. Esse padrão reflete a dor visceral decorrente da obstrução do ducto cístico, perdura por mais de 4 horas, ao contrário da "cólica biliar", que tem duração inferior. Quando a vesícula se inflama surge a dor parietal. Há piora da dor com a movimentação e com a inspiração profunda. O quadro é acompanhado de anorexia, náuseas e vômitos, que não são tão intensos quanto na pancreatite e na obstrução intestinal. A temperatura, geralmente, varia de 37,2 a $38,8^{\circ} \mathrm{C}$, a hiperpirexia é frequiente e a taquicardia é moderada.

Ao exame físico geral, $20 \%$ dos pacientes estão ictéricos. Geralmente a icterícia é branda (bilirrubina total $<4,0 \mathrm{mg} / \mathrm{dl}$ ). Cerca de $40 \%$ dos pacientes ictéricos, com colecistite aguda apresentam cálculos no ducto biliar comum. Nos outros casos a icterícia parece decorrer do edema pericoledociano pela impactação do cálculo no infundíbulo da vesícula (Sín- 
drome de Mirizzi), da colestase intra-hepática ou do aumento da permeabilidade do epitélio da vesícula à bilirrubina conjugada. ${ }^{16}$

Na palpação da região da região subcostal direita, observam-se sinais de irritação peritoneal traduzidas por dolorimento, contratura muscular e dor à descompressão brusca. Se o paciente respira, profundamente, durante a palpação profunda da área subcostal, sente dor aguda que o obriga a interromper a inspiração (Sinal de Murphy). Nesta manobra, a vesícula inflamada é atingida pela mão do examinador. Em aproximadamente um terço dos pacientes, palpase a vesícula biliar ou um plastão, no restante dos casos a fibrose crônica limita o aumento do órgão ou a defesa do paciente e a hepatomegalia impedem o contato da vesícula com a mão do examimador. Quando a dor e a sensibilidade se tornam intensas, a febre excede $38,8^{\circ} \mathrm{C}$, a leucocitose se eleva acima de $15.000 /$ $\mathrm{mm}^{3}$ e o paciente apresenta calafrios, o empiema vesicular ou a perfuração podem estar presentes ${ }^{15}$, sendo necessária a operação de urgência.

É fundamental enfatizar que a descrição clínica típica está ausente em um terço dos pacientes acima de 60 anos e em $20 \%$ dos pacientes internados em Centro de Terapia Intensiva. Estes pacientes podem apresentar febre, confusão mental e alterações da perfusão periférica; os sinais de defesa peritoneal não aparecem e às vezes é possível palpar a vesícula ou um plastrão. O quadro insidioso pode levar ao protelamento da operação com aumento das taxas de complicação e mortalidade

Durante a crise, o número de leucócitos é, em média, de 12.000/ $\mathrm{mm}^{3}$ e há desvio à esquerda. Elevações discretas dos níveis séricos de bilirrubinas, fosfatase alcalina e das aminotransferases são freqüentes e atribuídas à inflamação do parênquima hepático e ou ductos biliares; a elevação progressiva e acentuada da bilurrubina direta sugere coledocolitíase. A amilase pode atingir níveis de 500U/dl e elevações maiores sugerem pancreatite.

A ultrassonografia é o exame preferido para avaliação inicial, porque pode ser realizado rapidamente, não é invasivo, não se utiliza de radiação ionizante, não depende das funções de excreção hepática, é mais barato, detecta dilatação dos ductos biliares e fornece imagens de órgãos adjacentes. Ainda, é um exame útil na avaliação de gestantes. $\mathrm{O}$ "íleo adinâmico", a obesidade e a localização dos cálculos no infundíbulo e no ducto cístico são fatores limitantes. Embora o exame em algumas situações não confirme o diag- nóstico de colecistite aguda, os cálculos são demonstrados na maioria dos pacientes. Os achados de espessamento da parede vesicular, lama biliar, líquido perivesicular, distenção biliar e hipersensibilidade ecográfica local, apesar de acrescentar sensibilidade e especificidade, são apenas sugestivos e não conclusivos de colecistite aguda. Esses sinais podem estar presentes em pacientes com colecistite crônica, insuficiência cardíaca congestiva, insuficiência renal, pancreatite, sepse, úlcera perfurada e abscessos intraabdominais.

A incidência de litíase biliar em pacientes que apresentam abdome agudo de diversas etiologias é de aproximadamente $30 \%{ }^{17}$; desta forma, é necessário que haja critérios seguros para o estabelecimento do diagnóstico de colecistite aguda, ante a incerteza com a avaliação clínica e ultrassonográfica. A cintilografia da vias biliares é o exame de escolha para o diagnóstico de colesistite aguda calculosa nessa circunstância. Não há diferença entre a sensibilidade da cintilografia e da ultrassonografia que é de 97\%, mas a especialidade da cintilografia é maior que a da ultrassonografia (93 e $64 \%$, respectivamente) ${ }^{18}$. A sensibilidade da cintilografia é menor na colescistite acalculosa, porque o ducto cístico pode estar pérvio.

Na cintilografia, os análogos radioativos marcados do ácido iminodiacético (TC99 m HIDA, DISIDA) são injetados por via intravenosa, grande parte é captada pelos hepatócitos e excretada na bile. Normalmente, em 20 minutos visualiza-se a vesícula biliar de $80 \%$ dos pacientes e em 50 minutos de quase todos. A falta de marcação da vesícula biliar, com visualização da via biliar principal e duodenal, é um achado indicativo de colecistite aguda. Resultados falso-positivos são observados em pacientes com jejum prolongado, em regime de hiperalimentação parenteral total, em pancreopatas, em alcoólatras ou portadores de doença hepatocelular, o que justifica, nesses casos, cautela na interpretação do exame.$^{18}$ A cintilografia, além do problema de disponibilidade, tem a desvantagem de fornecer poucas informações sobre outros aspectos da afecção biliar. É um exame que pode ser reservado para pacientes com resultados sonográficos normais, mas com fortes suspeitas de colecistite aguda.

Os exames de tomografia computadorizada e ressonância magnética são menos utilizados para a avaliação de pacientes com suspeita de colecistite aguda, principalmente em função dos custos elevados. No entanto, ambos os exames são eficazes na demonstração dos achados diagnósticos da colecistite aguda. 
Particularmente, a ressonância magnética associada à colangiografia tem alta sensibilidade e especificidade na diferenciação entre colecistite crônica e agu$\mathrm{da}^{19}$. Inclusive, nos casos de colecistite aguda alitiásica e na síndrome de Mirizzi, a ressonância magnética pode ter papel fundamental na demonstração da anatomia e na confirmação diagnóstica. Por fim, discute-se, nos países com maior disponibilidade na realização de ressonância magnética, a necessidade deste exame para todos os pacientes com indicação de colecistectomia, considerando a avaliação das variações de anatomia dos ductos cístico e biliar, assim como a avaliação de possíveis cálculos na via biliar principal ${ }^{20}$. A escolha do exame de imagem, no nosso meio, recai sobre a ultrassonografia. Assim os dados clínicos e laboratoriais, associados aos achados ultrassonográficos, ainda que este exame não seja eficiente para verificar a permeabilidade do ducto cístico, permitem diagnóstico de colecistite aguda na maioria dos casos.

O paciente com colecistite aguda deve ser internado e colocado em jejum. Infundem-se soluções eletrolíticas para manter a hidratação, repor perda pelos vômitos ou déficit pela redução da ingesta por via oral; o objetivo é garantir o débito urinário adequado e eletrólitos plasmáticos, dentro da normalidade.

A analgesia pode ser obtida com a administração de espasmolíticos (N-butilbrometo de hioscina) associados à diclofenaco sódico intramuscular que pode suprimir a produção de muco pela vesícula biliar, ou indometocina, por via intravenosa, que teria a vantagem de inibir a síntese de prostaglandina e reduzir a pressão intravesicular. Caso não haja vômitos e prejuízo da função intestinal, dispensa-se a aspiração gástrica, o que diminui o desconforto do paciente.

A antibioticoterapia deve ser iniciada porque se sabe que a bile se tornará infectada em mais de $50 \%$ dos casos, em 48 horas, predominantemente por germes entéricos. Não é muito importante se o antibiótico tem ou não excreção biliar, o que se espera é um bom nível sérico. O esquema inicial deve consistir em um único agente; a cefoxitina pode ser suficiente para a maioria dos casos.

Os pacientes que evoluem com sepse requerem esquemas associativos que incluem aminoglicosídeo mais clindamicina ou metronidazol, ou imipenemcilastina, isoladamente. Na colecistite aguda simples, o processo infeccioso pode ser controlado pela remoção completa da vesícula e a terapia antimicrobiana ser mantida apenas por 24 horas. Nos pacientes com infecção intraperitoneal já estabelecida, os antibióti- cos são mantidos. A suspensão deverá ocorrer na ausência de febre, de icterícia, após normalização da contagem dos leucócitos, e a declaração do paciente de estar se sentido bem.

Aproximadamente $60 \%$ dos pacientes com colecistite aguda evoluem de maneira satisfatória com o tratamento conservador, cerca de $30 \%$ experimentam pouca melhora e em geral $10 \%$ necessitam de operação de urgência. É importante enfatizar que cerca de um terço dos pacientes que tem evolução satisfatória apresentam episódio recorrente de colecistite aguda em até 8 semanas, após o tratamento clínico inicial. Estes aspectos evolutivos da colecistite aguda podem ter contribuído para o estabelecimento histórico da controvérsia entre o tratamento cirúrgico precoce, realizado na internação hospitalar inicial, geralmente após 24 a 48 horas e o tratamento tardio, eletivo e programado entre 4 e 6 semanas após o episódio agudo. A mortalidade e a morbidez nas duas abordagens são similares. À parte das vantagens médicas, o custo total, o tempo de internação e os dias de trabalho perdidos favorecem do ponto de vista econômico a operação precoce. ${ }^{21}$

No contexto atual, a operação precoce, efetuada por equipes experientes, é a opção adotada para o tratamento da colecistite aguda calculosa e não calculosa. Deve ser enfatizado que operação precoce não significa operação de emergência. A abordagem em caráter de emergência está indicada em torno de $50 \%$ dos pacientes, sobretudo em idosos com colecistite aguda, que não respondem às medidas clínicas iniciais ou pioram na vigência do tratamento conservador. A presença de massa inflamatória no hipocôndrio direito, a detecção de gás na vesícula biliar e canais biliares, a peritonite generalizada e o desenvolvimento de obstrução intestinal devem ser tratados com operação de urgência.

A maioria das operações deve ser realizada no período de 24 a 48 horas da admissão, com o enfermo devidamente avaliado e preparado. A colecistectomia é a operação de escolha, e é possível executá-la em cerca de $95 \%$ dos casos. ${ }^{22}$ As indicações para exploração dos canais biliares são as mesmas de uma operação eletiva. A necessidade de procedimentos complementares à colecistectomia precoce equivale-se à colecistectomia retardada.

As vias de acesso empregadas são a laparotomia e a videolaparoscopia. A seleção do acesso é feita em função de fatores ligados ao paciente, à doença biliar e à formação profissional do cirurgião.A cole- 
cistectomia precoce e o acesso videolaparoscópico, quando possível, proporcionam os melhores resultados no tratamento da colecistite aguda. ${ }^{23,24}$

\subsection{3- Litíase na via biliar principal}

A incidência de litíase na via biliar principal (LVBP) varia de 8 a $18 \%$ em pacientes portadores de colelitíase sintomática. ${ }^{25}$ Dentre os pacientes submetidos à colecistectomia para tratamento de colelitíase, cerca de 10 a $15 \%$ apresentam cálculos no hepatocolédoco. ${ }^{26}$ A grande maioria dos cálculos presentes no hepatocolédoco são pequenos e provenientes da vesícula biliar. Estes cálculos podem passar para o duodeno, espontaneamente, ou impactar-se na papila provocando obstrução biliar, colangite e pancreatite biliar. ${ }^{27}$

Historicamente, os pacientes com colelitíase e suspeita clínica de coledocolitíase eram tratados por meio da exploração da via biliar principal durante a colecistectomia aberta, e em 50 a $60 \%$ dos casos a coledocolitíase se confirmava. Com o advento da colangiopancreatografia retrógrada endoscópica (CPRE) diagnóstica e terapêutica, houve ampliação da indicação do tratamento endoscópico ${ }^{28}$, o que reduziu a morbi-mortalidade da exploração do ducto biliar principal durante a colecistectomia. ${ }^{29}$

A esfincterotomia endoscópica foi introduzida em 1974 e empregada inicialmente para tratamento da litiase residual da via biliar. ${ }^{30}$ Entretanto, com a ampliação da indicação da colecistectomia por videolaparoscopia, a colangiografia retrógrada endoscópica (CRE) associada à esfincterectomia (ES) passou a ser uma boa alternativa para o tratamento da litíase biliar. Os pacientes com suspeita clínica de coledocolitíase, confirmada por meio da CRE , podem ser submetidos à ES na fase pré-operatória da colecistectomia por videolaparoscopia.

A colecistectomia associada à coledocolitotomia e derivação bilioentérica é uma opção que pode prevenir recorrências da LVBP nos pacientes que apresentam via biliar com mais de 1,5 ou $2 \mathrm{~cm}$ de diâmetro, cálculos grandes, cálculo múltiplos e alterações anatômicas e funcionais do colédoco que propiciam a formação de cálculos primários, tais como dilatação ou divertículo. ${ }^{29}$ Existem duas modalidades de coledocoenterostomia para a litíase do colédoco: a coledocojejunostomia com reconstrução em Y de Roux e a coledocoduodenostomia.

A coledocojejunostomia é uma boa opção para pacientes com cálculos primários, diâmetro da via biliar igual ou superior a $15 \mathrm{~mm}$ ou divertículo periampolar. Esta modalidade de derivação biliar não é normalmente considerada uma boa opção para o tratamento da LVBP em função da maior complexidade técnica e das limitações para a abordagem endoscópica que pode ser necessária em casos de litíase recorrente. ${ }^{31}$

A coledocoduodenostomia é um procedimento tecnicamente mais fácil e rápido, e indicado em pacientes com maior risco cirúrgico. A anastomose laterolateral entre a porção anterior da via biliar principal com a anterior do bulbo duodenal pode ser realizada com facilidade por via laparoscópica. Entretanto este tipo de anastomose predispõe ao acúmulo de resíduos alimentares na via biliar distal, o que favorece o desenvolvimento de colangite e abscesso hepático-a denominada sump syndrome. ${ }^{32}$

\subsection{4- Pancreatite aguda biliar}

A pancreatite aguda biliar (PAB) acomete cerca de $5 \%$ dos pacientes submetidos à colecistectomia, especialmente aqueles portadores de cálculos pequenos, menores do que $5 \mathrm{~mm}$ de diâmetro ou com minilitíase. ${ }^{33}$

O diagnóstico de Pancreatite Aguda é baseado na presença de pelo menos dois dos três critérios que se seguem: 1) dor em abdome superior; 2) amilase e/ ou lípase séricas iguais ou maiores a três vezes o valor normal; 3) achados na TC ou RNM característicos de pancreatite aguda. ${ }^{34} \mathrm{~A}$ PAB decorre da migração de cálculos da vesícula biliar para o colédoco, os quais geralmente são eliminados com as fezes e previne a recorrência da doença. A influência da permanência do cálculo no colédoco sobre a evolução da PAB após sua instalação ainda não está bem estabelecida, o que explica, em parte, a controvérsia acerca da indicação de procedimentos avaliativos para a via biliar, bem como do momento da remoção desses cálculos.

Estudos prospectivos sugerem que a remoção precoce do cálculo da via biliar principal (VBP) resulta em redução da morbidade dos pacientes e pode evitar a progressão da pancreatite branda para pancreatite grave. ${ }^{35}$ Por outro lado, há estudos demonstrando que a CPRE de rotina beneficiaria somente um pequeno número de pacientes com persistência do cálculo na VBP e que na maioria das vezes realiza-se um procedimento invasivo desnecessário, com seus riscos associados. ${ }^{36}$ Essas ponderações indicam a necessidade de identificar por meio de métodos menos invasivos, do tipo ultra-sonografia endoscópica ou colangiografia por ressonância nuclear magnética 
(CRNM), a existência de coledocolitíase com impactação do cálculo na papila após o surto de PAB. ${ }^{37}$

Considerando que a PAB é precedida, na grande maioria dos casos, de episódios de dor biliar, a colecistectomia, realizada após os primeiros surtos sintomáticos, pode prevenir essa complicação. As vantagens do emprego da via laparoscópica permitem a realização das colecistectomias em regime ambulatorial, o que reduz ou elimina as listas de espera ${ }^{11}$ e pode ainda diminuir a incidência de complicações como a colecistite aguda, a coledecolitíase, a colangite e a pancreatite aguda.

O diagnóstico e tratamento da litíase na VBP na era laparoscópica podem incluir a CRNM e CPRE com esfincterotomia (ES) pré-operatória ou CPRE com ES pré-operatória seguidas de colecistectomia laparoscópica; colangiografia intra-operatória (CIO) seguida de exploração aberta ou laparoscópica do ducto biliar comum mais colecistectomia, ou CPRE com ES no pós-operatório da colecistectomia. ${ }^{36}$

Apesar da melhora dos cuidados de terapia intensiva nas últimas décadas, a taxa de mortalidade na PA não declinou de forma significativa. Dentre os óbitos, cerca de $50 \%$ ocorrem na fase precoce, isto é, nos primeiros 14 dias da admissão, e decorrem, principalmente, da síndrome da resposta inflamatória sistêmica (SIRS), secundária à necrose pancreática. Os óbitos remanescentes ocorrem na fase tardia, em função de complicações infecciosas, decorrentes também da necrose pancreática. ${ }^{38}$

A gravidade da PAB e o acesso ao sistema de saúde, em particular, a acessibilidade aos hospitais e aos seus recursos de cuidados intensivos influenciam no prognóstico. Os pacientes com PAB, na forma grave, requerem cuidados que inicialmente podem ser prestados em salas de estabilização clínica e depois mantidos e ampliados nas unidades de terapia intensiva. Os casos de PAB branda podem ser admitidos nos leitos de observação e depois serem conduzidos nas enfermarias. Todavia, a oferta desses recursos nos hospitais públicos de referência em urgência, no nosso meio, é geralmente insuficiente e inadequada: o número de leitos disponíveis é reduzido, o que associado à superlotação do hospital pode comprometer o suporte clínico-cirúrgico e consequentemente os resultados do tratamento de doenças graves. ${ }^{39,40}$

$\mathrm{O}$ acesso ao atendimento hospitalar ordenado pela regulação médica de urgência, a melhora no suporte clínico, a ampliação significativa do emprego da RNM, da colecistectomia por videolaparoscopia e da terapia intensiva, no conjunto, e da forma como têm sido aplicados, não foram suficientes para modificar o perfil de mortalidade na PAB no nosso meio. Na avaliação de 267 casos de PAB tratado no Hospital das Clínicas de Ribeirão Preto entre 1995 a 2004, a mortalidade geral foi de $11,6 \%$, pouco acima do limite superior registrado na literatura para a pancreatite aguda quando se considera todas as etiologias (variação de 2 a 9\%). Na PAB branda a mortalidade geral observada foi de $3,8 \%,{ }^{41}$ semelhante aos achados da literatura, em média, de 3\%, com variação de 1 a $7 \% .{ }^{43}$ Nesse estudo, a mortalidade geral para a PAB grave foi de $27,9 \%,{ }^{39}$ e está dentro dos limites observados na literatura; de $8 \%$ a $39 \%$, com média de $17 \% .{ }^{34}$

\section{3- COLECISTECTOMIA: PREPARO PERI- OPERATÓRIO E ASPECTOS TÉCNICOS}

O paciente é orientado a permanecer em jejum por 8 horas, e no banho que precede a operação ter atenção especial com limpeza da parede abdominal e do umbigo. Na recepção do centro cirúrgico, o paciente é orientado a urinar, o que dispensa a sondagem vesical e evita a lesão da bexiga cheia durante o acesso videolaparoscópico. A tricotomia, se necessária, é realizada imediatamente antes da operação. $\mathrm{Na}$ indução anestésica faz se a antibioticoprofilaxia que pode se restringir a uma dose apenas, caso não haja intercorrências durante a colecistectomia. Antes do acesso videolaparoscópico à cavidade abdominal, a sondagem orogástrica deve ser feita para evitar lesões gástricas. No fim da operação, a sonda gástrica pode ser removida. $\mathrm{O}$ acesso à cavidade abdominal pode ser obtido por meio de:

\section{1- Laparotomia}

Mediana, paramediana suparumbilical ou preferencialmente subcostal na extensão de 8 a $12 \mathrm{~cm} \mathrm{~A}$ exposição do campo operatório e particularmente do colo da vesícula e da via biliar principal é obtida com o emprego de afastadores de Doyen colocados no ângulo hepático do cólon e no lobo direito do fígado protegidos com compressa, mais a retração manual da primeira porção do duodeno e do antro gástrico.

\section{2- Minilaparotomia}

Incisão de aproximadamente cinco cm lateral a linha média no quadrante superior direito, com secção da maior parte do músculo reto abdominal como ocorre na incisão subcostal para a colescistectomia por laparotomia. 


\section{3- Laparoscopia}

Introdução de 4 trocarteres, dois de $10 \mathrm{~mm}$ e dois de $5 \mathrm{~mm}$. Um trocarte de $10 \mathrm{~mm}$ e introduzido transumbilical mediante pequena incisão que atinge $o$ peritônio e acomoda de forma justa a sua camisa. Esse procedimento dispensa a punção para realização do pneumoperitônio com a agulha de Veress, o que evita lesões intestinais e vasculares. O pneumoperitônio é obtido por meio de insuflador automático que deixa de insuflar quando a pressão intrabdominal atinge níveis desejados de 10 a $12 \mathrm{mmHg}$. A velocidade inicial de insuflação é de um litro por minuto de $\mathrm{CO}_{2}$ e pode atingir dois litros por minuto quando o abdômen já está distendido A insuflação gradativa da cavidade abdominal evita embolia gasosa e reduz a dor no ombro no pós-operatório. O segundo trocarte, também de $10 \mathrm{~mm}$ é colocado à distância de $4 \mathrm{a} 5 \mathrm{~cm}$ do apêndice xifóide e à direita do ligamento falciforme, sob visão direta. Dentre os demais trocarteres de $5 \mathrm{~mm}$, o primeiro é introduzido no nível da linha médioclavicular, abaixo do rebordo costal e o seguinte no nível da linha axilar anterior, na altura da cicatriz umbilical.

$\mathrm{O}$ acesso por via vaginal parece promissor com o emprego de instrumentos de extremidade flexível. Todavia, no diálogo com o paciente no pré-operatório o cirurgião não deve se comprometer com a modalidade do acesso. A conversão de um acesso para outro não é demérito. O compromisso maior do médico é como tratamento da doença vesicular por meio de um procedimento seguro.

Os passos técnicos que se seguem, independente da via de acesso empregada são semelhantes (Figura 2):

- Liberação de eventuais aderências da vesícula com o duodeno, epiploon e colon;

- Exposição do fundo e do infundíbulo vesicular (bolsa de Hartmann); caso a vesícula esteja tensa, aspira-se o seu conteúdo por meio de punção do fundo com agulha de grosso calibre;

- Tração superior do fundo da vesícula e lateral do infundíbulo para expor o triângulo de Calot delimitado pela artéria cística superiormente, pelo ducto hepático medialmente e pelo ducto cístico lateralmente. Nesse passo a tração vertical da bolsa de Hartmann pode distorcer a anatomia com tração do colédoco que pode ser confundido com o ducto cístico e precipitar a lesão da via biliar;

- A dissecção se inicia pelo colo da vesícula com aber- tura do peritônio e tração suave do mesmo no sentido do ducto cístico para o colédoco. A liberação do peritônio expõe o linfonodo cístico e a junção do ducto cístico com o hepatocolédoco. Na seqüência isola-se a artéria cística e seus ramos anterior e posterior, mais frequentemente identificados na cirurgia videolaparoscópica;

- Caso haja indicação de colagiografia transoperatória com o objetivo de definir a anatomia da via biliar ou identificar a presença de coledocolitíase (antecedentes de colestase, pancreatite aguda biliar) aplica-se uma ligadura ou grampo no ducto cístico próximo à sua união com a vesícula e realiza uma incisão na sua face anterior (40 a 50\% do seu diâmetro). Um cateter de quatro a cinco $\mathrm{F}$ acoplado a uma seringa com soro fisiológico de $20 \mathrm{ml}$ é introduzido na abertura do ducto cístico até atingir o colédoco. Caso o cateter não possua balão ou oliva metálica na extremidade, procede-se a sua fixação ao ducto cístico por meio de falsa ligadura ou grampo que permite o fluxo livre de soro. Na seqüência, duas grafias são realizadas: uma com $3 \mathrm{ml}$ de contraste para detecção de cálculos pequenos e outra com $10 \mathrm{ml}$ para avaliar toda a extensão da via biliar principal (Figura 2c e Figura 3);

- Procede-se a ligadura da artéria cística com fio ou grampo, após identificação segura do seu percurso entre a sua origem e a entrada na vesícula. A artéria cística é um vaso pequeno. Dessa forma, um vaso maior e mais calibroso, nessa topografia, requer uma dissecção cautelosa para evitar a ligadura inadvertida do que pode corresponder a artéria hepática direita;

- Após secção da artéria cística, a tração do infundíbulo permite esticar o ducto cístico e demonstrar a sua junção com o hepatocolédoco. Dessa forma, procede se a ligadura do ducto cístico com fio ou grampo a cerca de três a cinco $\mathrm{mm}$ da via biliar principal para evitar lesões;

- A liberação da vesícula do seu leito no fígado é realizada por meio de abertura da reflexão peritoneal de ambos os lados do infundíbulo e, preferencialmente, com movimentos laterais da bolsa de Hartmann se disseca ambos os lados da vesícula com tesoura e ou gancho em direção ao fundo. Os vasos mais calibrosos e as estruturas mais firmes devem ser ligados para evitar sangramento e vazamento biliar no pós-operatório. Quando a dissecção se aproxima do fundo, revisa se a hemostasia do leito 
vesicular e verifica-se se há vazamento biliar no local, medida que pode ser facilitada com a instilação de soro fisiológico;

- A remoção da vesícula, no acesso por videolaparoscopia, é feita, habitualmente pelo orifício umbilical. Dessa forma, a câmera é transferida para o orifício subxifoideo e uma pinça forte com dentes é introduzida no trocarte do orifício umbilical para remover a vesícula após preensão do ducto cístico. Após a retirada do trocarte umbilical juntamente com a pinça, a vesícula pode permanecer presa no orifício umbilical. Nessa eventualidade, o orifício na aponeurose umbilical pode ser ampliado ou a porção exteriorizada do infundíbulo vesicular pode ser aberta para aspiração de bile e cálculos. As vesículas com parede inflamada ou com muitos cálculos e de paredes finas podem ser removidas em bolsa de plástico confeccionada com o punho de luva cirúrgica para evitar contaminação e perdas de conteúdo para a cavidade abdominal;

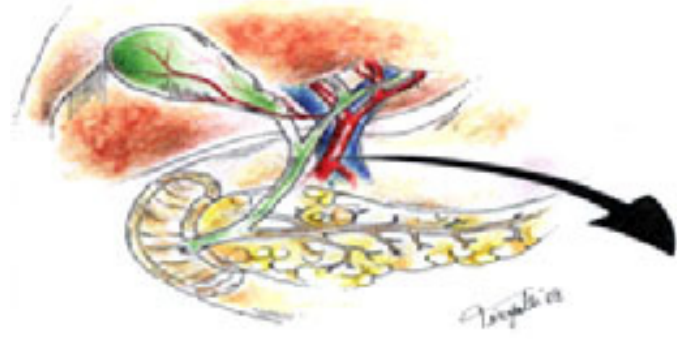

A

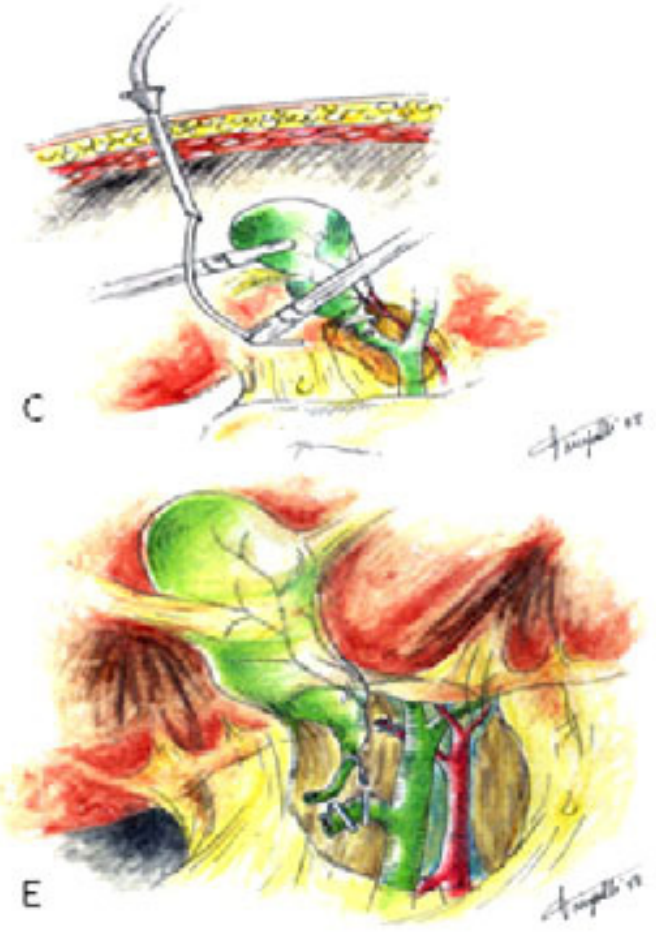

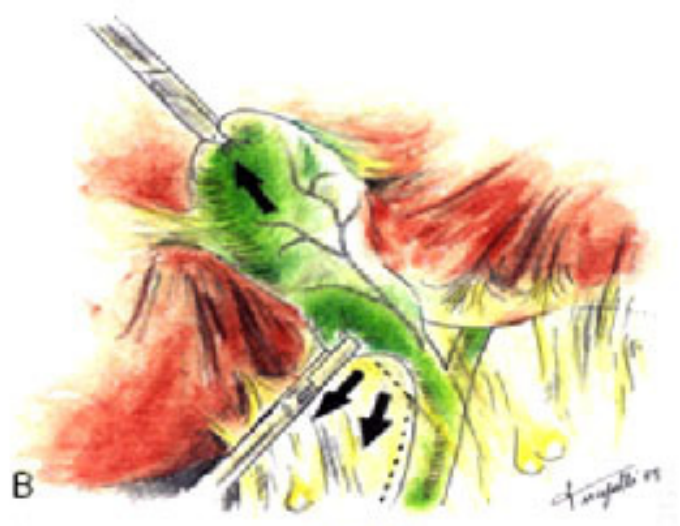

D
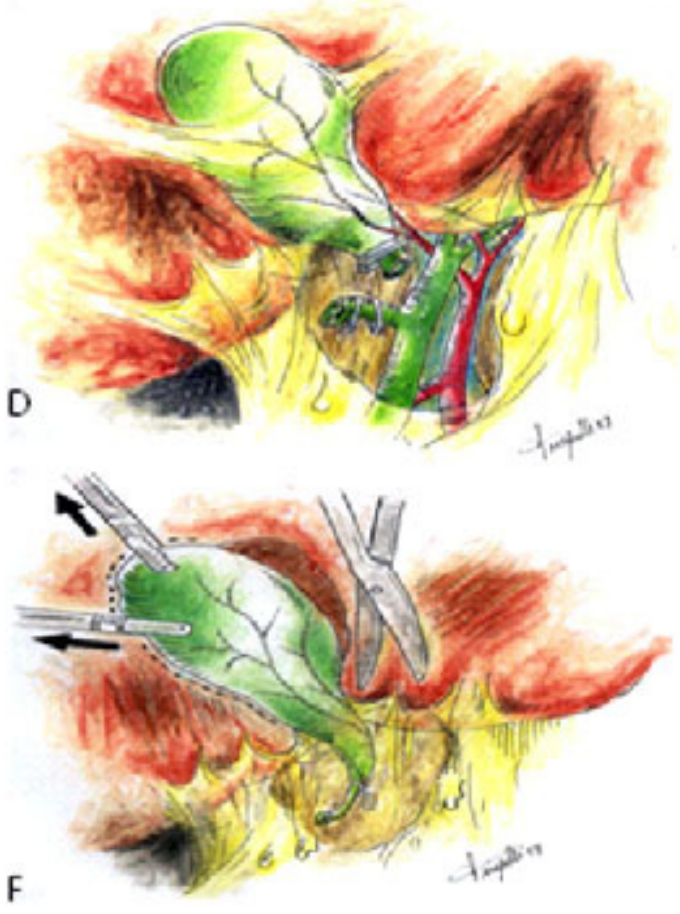

Figura 2: Detalhe da anatomia habitual da via biliar e suas relações com o pedículo hepático, o duodeno e o pâncreas (A); Tração superior do fundo vesicular e lateral do infundíbulo a ser exercida corretamente durante a colecistectomia; (B) abertura da face anterior do ducto cístico em sua união com a vesícula para introdução de cateter para colangiografia transoperatória (C); Ligadura e secção do ducto cístico (D) da artéria cística (E) e liberação do peritônio que recobre a vesícula biliar e a fixa ao fígado. 

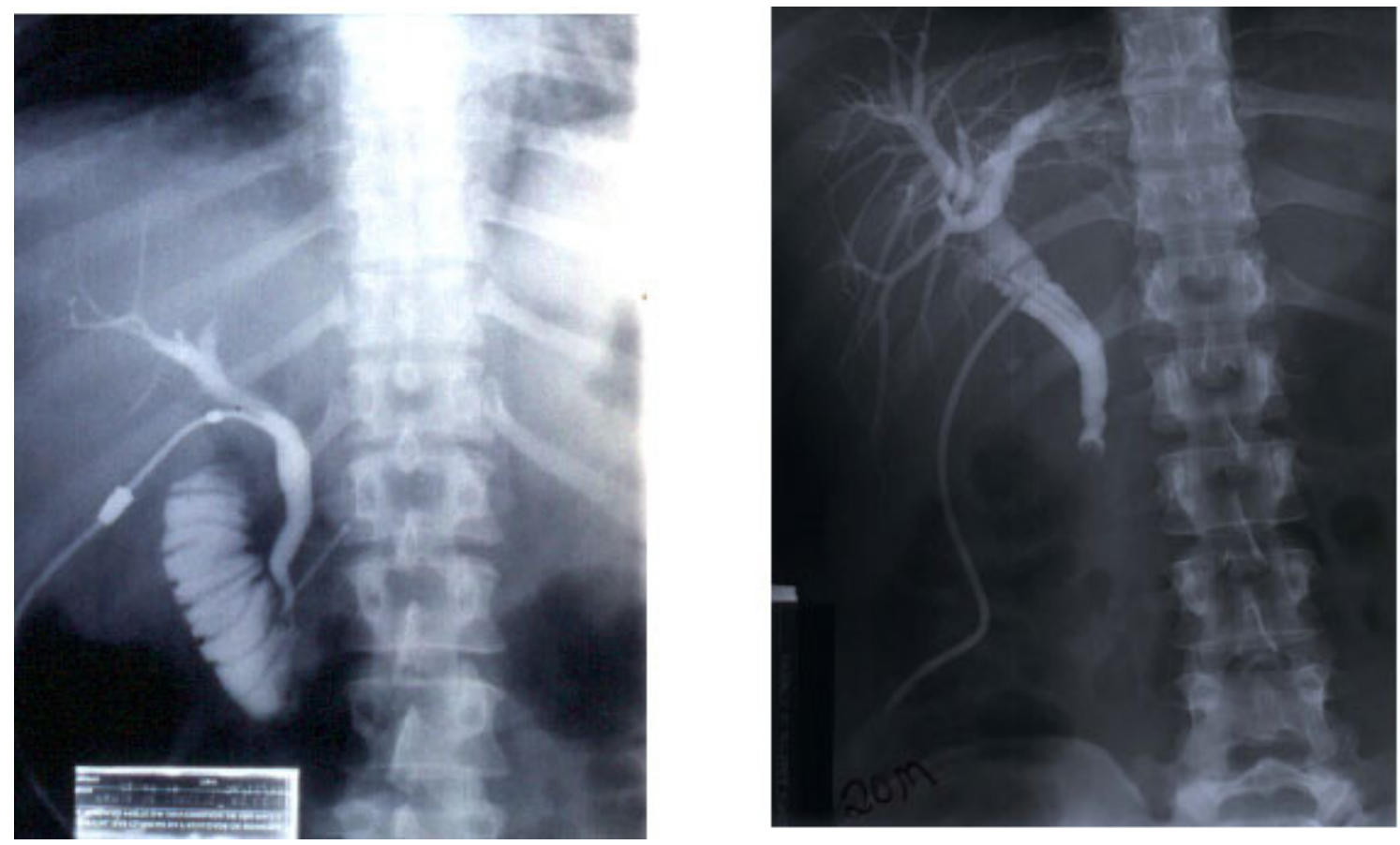

Figura 3: Colangigrafias obtidas no transoperatório de colecistectomia. Exame normal obtido pela introdução de cânula metálica no ducto cístico com o contraste na via biliar principal, no canal pancreático e no duodeno (A). Em (B) colangiografia pós-operatória obtida pelo dreno T (Kher) introduzido na via biliar principal que está dilatada e com cálculo impactado (imagem em taça invertida) impedindo a passagem de contraste para o duodeno. Nesse caso, a remoção do cálculo foi feita mediante papiloesfincterotomia endoscópica.

- A drenagem da cavidade abdominal é medida de exceção e quando indicado emprega-se o sistema fechado. Nos casos de gangrena vesicular, abscesso perivesicular, rotura da vesícula com grande escape de bile, dissecção difícil, necessidade de abertura do colédoco, entre outros, recomenda-se a drenagem da cavidade abdominal;

- A síntese da parede abdominal é feita de maneira habitual; no acesso por videolaparoscopia, a aponeurose da região umbilical deve ser suturada para evitar o aparecimento de hérnia, assim como o orifício subxifoideo nas pessoas magras. Os orifícios para os trocarteres de $5 \mathrm{~mm}$ não requerem sutura da aponeurose.

A colecistostomia que consiste da drenagem da vesícula por meio de cateter do tipo Malecot introduzido no seu fundo por via percutânea ou mediante pequena incisão subcostal sob anestesia local é um procedimento seguro, eficaz e com excelentes resultados para pacientes com colecistite aguda, elevado risco cirúrgico e em sepse ${ }^{40}$ (Figura 4).

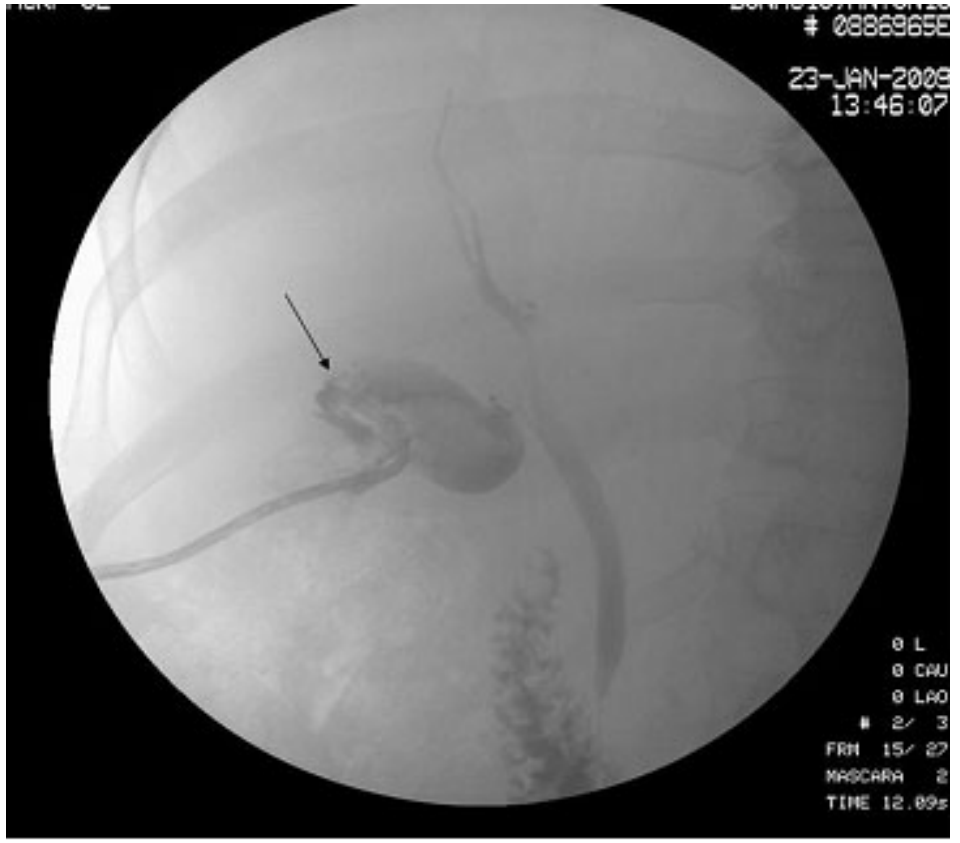

Figura 4: Colecistocolangiografia obtida após colecistostomia realizada por meio de punção percutânea da vesícula (seta) em paciente com 46 anos de idade admitido com sepse de origem biliar e colestase (bilirrubinas totais 13 e direta de $11,6 \mathrm{mg} / \mathrm{dl}$ ) de origem infecciosa, pois a via biliar principal estava normal. 


\section{4- TUMORES BENIGNOS DA VESÍCULA BILIAR}

A ampliação do emprego da ultrassonografia de abdômen na prática clínica passou a identificar com mais freqüência as lesões polipóides da vesícula biliar. Cerca de $5 \%$ das pessoas que se submetem a ultrassonografia de abdômen podem apresentar pólipos de vesícula. Esses tumores benignos podem ser de origem epitelial (adenomas), mesenquimal (fibromas, lipomas, hemangiomas) ou pseudotumores (pólipos de colesterol: tumores benignos mais freqüentes, pólipos inflamatórios e adenomiomas). ${ }^{43,44}$

A maioria das lesões polipóides é benigna e permanecem estáveis por muitos anos. A evolução das lesões pode ser avaliada por meio da ultrassonografia de abdômen a cada 3 ou 6 meses e se permanecerem estáveis, esse seguimento pode ser desnecessário após 2 anos. $^{45}$

A abordagem das lesões polipóides depende da presença de sintomas e da probabilidade de abrigar lesão maligna. Os pacientes com sintomas que possam ser atribuídos à presença de pólipo devem ser submetidos à colescistectomia. Adicionalmente, os pacientes que apresentam pólipos com risco de degeneração maligna (lesões maiores que 1 centímetro de diâmetro, solitárias e sésseis em pessoas com mais de 50 anos de idade) devem ser tratados. A colecistectomia por videolaparoscopia é a primeira opção a ser empregada. No ato cirúrgico a lesão deve ser submetida a exame anatomopatológico e se confirmada a presença de câncer a extensão da cirurgia deve ser redimensionada. Por outro lado, se no pré-operatório o risco da presença de neoplasia maligna é elevado (lesão $>$ que 2 centímetros) a colecistectomia via aberta é indicada. ${ }^{43}$

\section{5- CÂNCER DA VESÍCULA BILIAR}

É um câncer pouco freqüiente, mas no Brasil não há fonte segura sobre a sua incidência real ou estimada. Nos Estados Unidos da América do Norte a incidência é baixa (1,2 casos por 100.000 habitantes/ ano). Por outro lado, dentre os cânceres da via biliar é o mais freqüente, e se constitui no quinto tumor maligno mais diagnosticado do sistema digestório. ${ }^{46}$

A causa do câncer de vesícula é desconhecida, mas estudos epidemiológicos indicam que os processos irritativos e inflamatórios da vesícula são fatores de risco para o início do desenvolvimento da doença. ${ }^{47}$ Desta forma os fatores associados à doença biliar e, em especial, à litíase biliar têm associação elevada com o câncer de vesícula; 79 a 98\% dos pacientes possuem história prévia de colelitíase sintomática com cálculos grandes e de colesterol. A síndrome de Mirizzi caracterizada pela impactação dos cálculos com a consequiente irritação crônica da vesícula e a vesícula em porcelana que se caracteriza pela inflamação crônica e calcificação da parede vesicular está associada a um risco maior de câncer. ${ }^{48,49}$

O carcinoma de vesícula localizado não apresenta sintomas específicos. A dor no hipocôndrio direito, perda ponderal, anorexia, náuseas e vômitos, icterícia e distensão abdominal são os sintomas mais freqüentes. ${ }^{50}$ A presença de icterícia está associada a prognóstico ruim, com ressecabilidade cirúrgica em torno de $55 \%$. Na doença avançada os pacientes podem apresentar, também, massa palpável, fígado irregular e ascite. ${ }^{50}$

A ultrassonografia (US) de abdome, em geral, é o exame inicial mais realizado e pode diagnosticar lesões passíveis de cura. Tanto as imagens da US quanto as da tomografia computadorizada (TC) se correlacionam com o aspecto macroscópico do tumor. A presença de massa heterogênea, que ocupa o espaço subepático e que pode se apresentar com cálculos em seu interior é a forma mais freqüente de apresentação. ${ }^{51}$ A Ressonância Nuclear Magnética é sensível para detecção da extensão do tumor e pode determinar com boa precisão a invasão direta do fígado ou de estruturas adjacentes além de permitir a avaliação de estruturas vasculares e da via biliar principal definindo, assim, no pré-operatório, a ressecabilidade. ${ }^{52}$

Os marcadores tumorais CA 19-9 e CEA podem estar elevados no carcinoma de vesícula e contribuem para o diagnóstico, principalmente nos pacientes anictéricos. A sensibilidade desses marcadores é equivalente, mas a especificidade do CA19-9é maior que a do CEA $(90 \%$ contra $71 \%) .{ }^{53}$

Para os tumores superficiais Tis, T1a ou até mesmo T1b, a colecistectomia simples parece ser adequada, não se necessitando de ressecção ampliada (hepática) ou linfadenectomia hilar (Figura 5). Contudo, para estádios mais avançados (T2 ou mais), a maioria dos estudos sugere que algum tipo de ressecção hepática complementada com linfadenectomia hilar seja incluído para o seu tratamento. Os bons resultados dependem da margem hepática livre de neoplasia e da linfadenectomia regional adequada. Assim, além da colecistectomia, a ressecção dos segmentos IV-B e $\mathrm{V}$, também denominada bissegmentectomia central inferior (S4b+S5), a hepatectomia central (ressecção dos segmentos IV, V e VIII) e a hepatectomia direita 


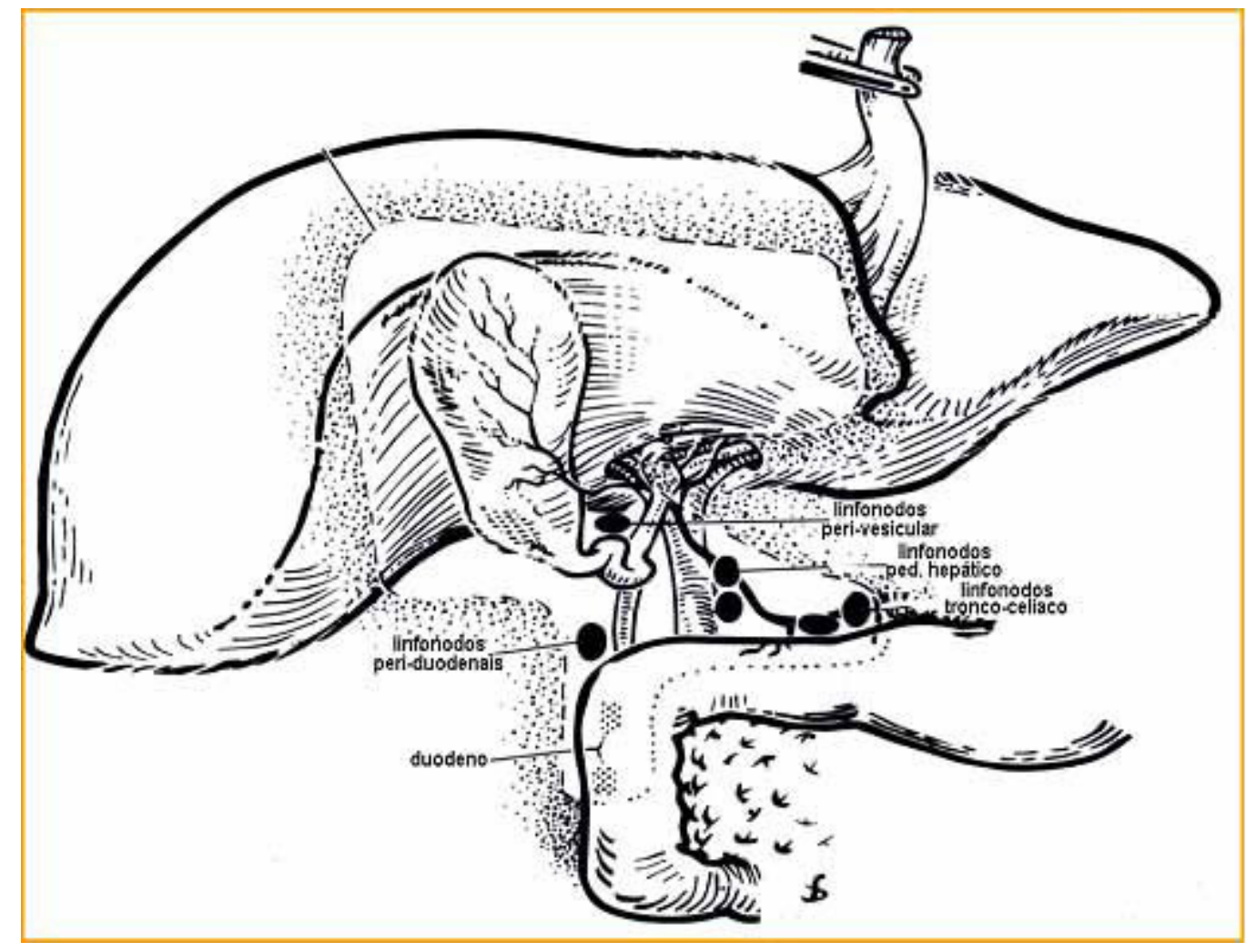

Figura 5: Esquema de colecistectomia ampliada para tratamento de câncer da vesícula com ressecção hepática e linfadenectomia. ${ }^{56}$

ampliada para o segmento IV, têm sido os tipos de ressecção empregados para o tratamento do carcinoma invasor da vesícula biliar nos estádios T1b até T3. ${ }^{54}$

A sobrevida global para o câncer de vesícula é baixa em função da invasão local, da disseminação peritoneal e da extensa infiltração linfática precoce. A sobrevida nos pacientes com carcinoma de vesícula é diretamente proporcional à espessura do tumor, à presença de comprometimento de linfonodos (estádio TNM) e à cirurgia sem margens comprometidas (R0). Após ressecção curativa (R0), a sobrevida tem variado de $60 \%$ a $80 \%$ em cinco anos para os tumores T2, e de $15 \%$ a $50 \%$ em cinco anos para os tumores T3. ${ }^{55}$

\section{6- RESULTADOS E COMPLICAÇÕES DA CO- LECISTECTOMIA}

A conseqüência mais comum da colecistectomia é o aumento da frequiência das evacuações que acomete menos de $5 \%$ e responde bem às medidas habituais de orientação alimentar e antidiarreicos. A mortalidade após colecistectomia é baixa, $0,1 \%$ para o acesso por videolaparoscopia e $0,5 \%$ para o acesso por laparotomia, onde as complicações cardiorrespiratórias são mais freqüientes. ${ }^{4}$
A permanência hospitalar na colecistectomia por laparotomia é de dois a três dias enquanto na via laparoscópica a operação pode ser feita em regime ambulatorial e o retorno as atividade laborais, em geral, ocorre após 7 a 10 dias. $^{4,10,11}$

A maior desvantagem da colecistectomia via laparoscópica é a incidência mais elevada de lesão traumática da via biliar: de 0,2 a $0,4 \%$ em comparação a $0,1 \%$ no tratamento por laparotomia. ${ }^{4} \mathrm{~A}$ inexperiência do cirurgião, a colecistite aguda e a vesícula escleroatrófica são fatores associados à maior incidência de lesão traumática da via biliar. A lesão traumática da via biliar, por sua vez, também pode ser agravada por dificuldade de acesso oportuno ao tratamento e, não raramente, por reoperações executadas por profissionais sem formação especializada. Esses fatores podem transformar lesões mais acessíveis às derivações biliodigestivas efetivas em lesões mais complexas (Figura 6). Alguns pacientes com colestase crônica secundária à lesão traumática da via biliar podem apresentar lesões no fígado como fibrose e cirrose com hipertensão portal, onde a dúvida entre a indicação ou revisão da derivação biliar e o transplante hepático, bem como a evolução pós-operatória ainda persiste. 

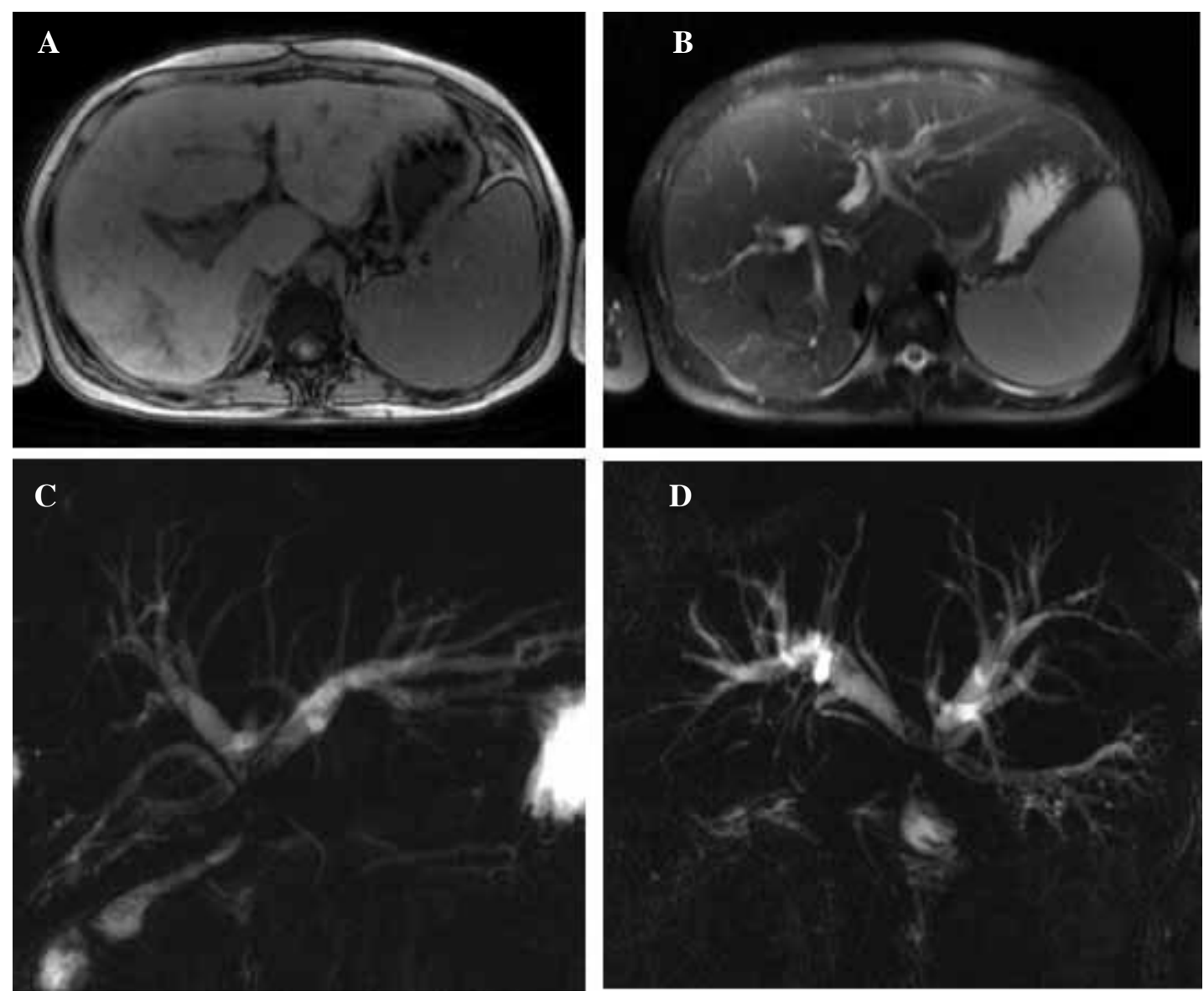

Figura 6: Ressonância nuclear magnética de mulher com 20 anos de idade e lesão traumática da via biliar há 3 anos decorrente de colecistectomia por videolaparoscopia em serviço de média complexidade. Após duas tentativas de reparo da via biliar sem sucesso a paciente foi encaminhada ao serviço de referência terciária com colestase, lesão do tipo E3 de Strasberg ${ }^{57}$, hepatoesplenomegalia e varizes de esôfago, onde foi submetida à DBJ. A) Imagem axial pesada em T1 - hepatoesplenomegalia notando-se heterogeneidade no lobo direito (fibrose), B) Imagem axial pesada em T2 - hepatoesplenomegalia notando-se dilatação das vias biliares intra-hepáticas, C e D) Colangiografia por ressonância magnética (Imagens coronais oblíquas pesadas em T2) - Dilatação das vias biliares intrahepáticas com lesão da junção dos ductos hepáticos e pequenos cálculos intra-hepáticos. Colédoco e ducto pancreático de calibre preservado. Fonte: Centro de Ciências da Imagem do HCFMRP-USP.

Santos JS, Sankarankutty AK, Salgado Júnior W, kemp R, Módena JLP, Elias Júnior J, Castro e Silva Júnior O. Cholecystectomy: Technical aspects and indications for the treatment of biliary calculi and neoplasms. Medicina (Ribeirão Preto) 2008; 41 (4): 449-64.

ABSTRACT: The surgical removal of the gallbladder has been practiced for more than a century and in the last 25 years has undergone fundamental changes in its technique, specially regarding access as well as the exploration of the biliary tree. The most frequent indications for cholecystectomy are gallbladder stones with its complications (acute cholecystitis, choledocolithiasis, cholangitis, acute biliary pancreatitis) and neoplasia of the gallbladder. Initially, cholecystectomies for the treatment of gallbladder stones, were performed through laparotomies. By the end of the 20th century, these surgeries were being performed through progressively smaller incisions, such as minilaparotomy and was soon followed by videolaparoscopy, which is now considered the gold standard. More recently, this procedure is being carried out, although still in the experimental stage, through a transgastric or transvaginal access. The benefits of the videolaparoscopic access is incontestable, but its use requires caution and training in order to minimize the incidence of traumatic lesions of the biliary tree or other structures.

Keywords: Cholecystectomy. Lithiasis. Biliary Tract Diseases. Cholelithiasis. Cholecystitis, Acute. Choledocholithiasis. Pancreatitis. Acute Disease. Gallbladder Neoplasms. 


\section{REFERÊNCIAS BIBLIOGRÁFICAS}

1 - Kalloo AN, Singh VK, Jagannath SB, Niiyama H, Hill SL, Vaughn $\mathrm{CH}$ et al. Flexible transgastric peritoneoscopy: a novel approach to diagnostic and therapeutic interventions in the peritoneal cavity. Gastrointest. endosc. 2004; 60 (1): 114-7.

2 - Marescaux J, Dallemagne B, Perretta S, Wattiez A, Mutter D, Coumaros D. Surgery without scars: report of transluminal cholecystectomy in a human being. Arch. surg. 2007; 142(9): 823-7.

3 - Hermann RE. The spectrum of biliary stone disease. Am. j. surg. 1989; 158:171-3

4 - Beckingham IJ. ABC of diseases of liver, pancreas, and biliary system-gallstone disease. BMJ. 2001; 322: 91-4.

5 - McSherry CK, Ferstenberg H, Callhoum F, Lahman E, Virshup $M$. The natural history of diagnose gallstone disease in symptomatic and asymptomatic patients. Ann. surg. 1985; 202: 59-63.

6 - Flasar MH, Goldberg E. Acute abdominal pain. Med. clin. North America. 2006; 90: 481-503.

7 - Flasar MH,Cross R, Goldberg E, Acute abdominal pain. Prim. care. 2006; 33: 659-84.

8 - Gunn, A and Keddie N. Some clinical observations on patients with Gallstones. Lancet. 1972; 2: 7771.

9 - Sakorafas GH, Milingos D, Peros G. Asymptomatic cholelithiasis: is cholecystectomy really needed? A critical reappraisal 15 years after the introduction of laparoscopic cholecystectomy. Dig. dis. sci. 2007; 52(5):1313-25.

10 - Ceneviva R, Santos JS, Mente ED, Sankarankutty AK, Castro e Silva Jr O. Colecistectomia Videolaparoscópica como cirurgia ambulatorial. Rev. Col. Bras. Cir. 1999; 42-5.

11 - Santos JS, Silva MB, Zampas AG, Sankarankutty AK, Campos AD, Ceneviva R. Mutirões de colecistectomia por videolaparoscopia em regime de cirurgia ambulatorial. Acta cir. bras. São Paulo. 2001; 16 (Supl. 1): 52-6.

12 - Browning JD, Sreenarasimhaiah J. Gallstone disease. In. Feldman M, Friedman LS, Brandt LJ. Gastrointestinal and Liver Disease - Pathophysiology/Diagnosis/Management. $8^{\text {a }}$. ed. Philadelphia, Saunders Elselvier 2006; v.1, p.1397-1418

13 - Fukumaga HF. Gallbladder bacteriology, histology and gallstones. Study of unselected specimes in Honolulu. Arch. surg. 1973; 106: 169-71.

14 - Jhonson, L.B. The importante os early diagnosis of acute acalculus cholecystitis. Surg. gynecol. obstet. 1987; 164: 197-203.

15 - Rigas B, Torosis J, Mcdougall CJ, Vener KJ, Spiro HM. The circadian rhytim of billiary colic. J. clin. gastroenterol. 1990; 12: 409-14.

16 - Dumont AE. Significance of hyperbilirubinemia in acute cholecystitis. Surg. gynecol. obstet. 1976; 142: 855-7.

17 - Carrol BA. Preferred imaging techniques for the diagnosis of cholecystitis and cholethiasis. Ann. surg. 1989; 210: 1-12.

18 - Samuels BI, Freitas JE, Bree RL, Schwab RE, Heller ST. A comparison of radionucleotide hapatobiliary imaging and real time ultrassound for the detection of acute cholecystitis. Radiology. 1983; 147: 207-10.
19 - Altun E, Semelka RC, Elias J, Jr. Braga L, Voultsinos V, Patel J, Balci NC, Woosley JT. Acute cholecystitis: MR findings and differentiation from chronic cholecystitis. Radiology. 2007; 244:174-183

20 - Jendresen MB, Thorbøll JE, Adamsen S, Nielsen H, Grønvall $\mathrm{S}$, Hart-Hansen $\mathrm{O}$. Preoperative routine magnetic resonance cholangiopancreatography before laparoscopic cholecystectomy: a prospective study. Eur. j. surg. 2002; 168 (12): 690-4

21 - Norrby S, Herlyn P, Holmin T, Sjördal R, Tagesson C. Early or delayed cholecystectomy in acute colecystitis? A clinical trial. Br. J. Surg. 1983; 70: 163-5.

22 - Andrade JI, Hsien TC, Martins Jr A, Coronato Neto S, Gandolfi PP, Scarpelini S, Ceneviva, R. Colecistite aguda tratada por operação precoce e retardada: Estudo prospectivo e randomizado. Rev. Col Bras. Cir. 1991; 18: 42-6.

23 - Johansson M, Thune A, Nelvin L, Stiernstam M, Westman B, Lundell L. Randomized clinical trial of open versus laparoscopic cholecystectomy in the treatment of acute cholecystitis. Br. j. surg. 2005 Jan;92(1):44-9

24 - Gurusamy KS, Samraj K. Early versus delayed laparoscopic cholecystectomy for acute cholecystitis. Cochrane database syst. rev. 2006 Oct 18;(4):CD005440.

25 - Ko Cw, Lee SP. Epidemiology and natural history of common bile duct stones and prediction of disease. Gastrointest. endosc. 2002; 56(6 Suppl): S165-9.

26 - Moreaux J. Prospective study of open cholecystectomy for calculous biliary disease. Br. j. surg. 1994; 81(1): 116-9.

27 - Fink AS. Current dilemmas in management of common duct stones. Surg. endosc. 1993; 7(4): 285-91

28 - Carr-Locke DL. Therapeutic role of ERCP in the management of suspect common bile duct stones. Gastrointest. endosc. 2002; 56(6 Suppl): S170-4.

29 - Schreurs WH, Juttmann JR, Stuifbergen WN, Oostvogel HJ, Van Vroonhoven TJ. Management of common bile duct stones: selective endocscopic retrograde cholangiography and esdoscopic sphincterotomy: short- and long-term results. Surg. endosc. 2002; 16(7): 1068-72.

30 - Kawai K, Akasaka Y, Murakami K, Tada M, Koli Y. Endoscopic sphincterotomy of the ampulla of Vater. Gastrointest. endosc. 1974; 20(4): 148-51.

31 - Uchiyama K, Onishi H, Tani M, Kinoshita H, Ueno M, Yamaue $\mathrm{H}$. Indication and procedure for treatment of hepatolithiasis. Arch. surg. 2002; 137(2): 149.

32 - Hiura A, Kim EC, Ikchara T, Matsumura Y, Mishima K, Ishida I. Hepatic abscess as a complication of the sump syndrome. J. hepatobiliary. pancreat. surg. 2000; 7(2): 231-5.

33 - Whitcomb DC. Acute Pancreatitis. N. Engl. j. med. 2006; 354(20): 2142-50.

34 - Banks PA, Freeman ML. Practice Guidelines in acute Pancreatitis. Am. j. gastroenterol. 2006; 101: 2379-400.

35 - Neoptolemos JP, London NJ, James D, Carr-Locke DL, Bailey IA, Fossard DP. Controlled trial of urgent endoscopic retrograde cholangiopancreatography end endoscopic sphincterotomy versus conservative treatment for acute pancreatitis due to gallstones. Lancet. 1988; 2: 979-83.

36 - Chang L, Lo S, Stabile BE, Lewis RJ, Toosie K, Virgilio C. Preoperative versus postoperative endoscopic retrograde 
cholangiopancreatography in mild to moderate gallstone pancreatitis. Ann. surg. 2000; 231: 82-7.

37 - Makary MA, Duncan MD, Harnmon J W, Freeswick PD, Bender JS, Bohlman M, Magnuson TH. The role of magnetic resonance cholangiography in the management of patients with gallstone pancreatitis. Ann. surg. 2005; 241: 119-24.

38 - Mutinga M, Rosenbluth A, Tenner SM, Odze RR, Sica GT, Banks PA. Does mortality occur early or late in acute pancreatitis. Int. j. pancreatol. 2000; 28: 91-5.

39 - Santos JS, Scarpelini S, Brasileiro SLL, Ferraz CA, Dallora MELV, Sá MFS. Avaliação do modelo de organização da unidade de emergência do HCFMRP-USP, adotando, como referência, as políticas nacionais de atenção às urgências e de humanização. Medicina (Ribeirão Preto) 2003; 36: 498515.

40 - Lopes SLB, Santos JS, Scarpelini S. The implementation of the medical regulation office and mobile emergency attendance system and its impact on the gravity profile of nontraumatic afflictions treated in a university hospital: a research study. BMC Health serv. res. 2007; 7: 173.

41 - Carvalho FR, Santos JS, Elias Junior J, Kemp R, Sankarankutty AK, Fukumori OY, Souza MCLA, Castro E Silva Junior O. The influence of treatment access regulation and technological resources on the mortality profile of acute biliary pancreatitis. Acta cir. bras. 2008; 23 (Supl 1): 143-9.

42 - Byrne MF, Suhocki P, Mitchell RM, Pappas TN, Stiffler HL, Jowell PS, Branch MS, Billie J: Percutaneous cholecystectomy in patents withy acute cholecistitis: Experience of 45 patients at a US referral center. 2003 197: 206-11

43 - Boulton RA, Adams DH: Gallbladder polyps: When to wait and when to act. Lancet. 349:817, 1997

44 - Yang HL, Sun YG, Wang Z. Polypoid lesions of the gallbladder: diagnosis and indications for surgery. Br. j. surg. 1992; 79: $227-9$.

45 - Lee KF, Wong, J, Li, JCM , Lai PBS. Polypoid lesions of the gallbladder. The Am. j. surg. 2004; 188: 186-90.

46 - Carriaga MT, Henson DE. Liver, gallbladder,extrahepatic bile ducts and pâncreas. Cancer. 1995; 75: 171-90.
47 - Serra I, Calvo A, Baez S et al. Risck factor for gallbladder cancer: An international collaborative case control study. Cancer. 1996; 78: 1515-17.

48 - Moerman CJ, LagerwaardFJ,Bueno de Mesquita et al. Gallstone size anda the risk of gallbladder cancer. Scand. j. gastroenterol. 1993; 28: 482-6.

49 - Stephen AE, Berger DL. Carcinoma in the porcelain gallbladder: A relationship revised. Surgery (St. Louis). 2001; 129: 699-703.

50 - Misra S, Chatuverdi A, Misra NC, Sharma ID. Carcinoma of the gallbladder. Lancet oncol. 2003; 4: 167-76.

51 - Kumar A, Aggarwal S. Carcinoma of the gallbladder: CT findings in 50 cases. Abdom. imaging. 1994; 19: 304-8.

52 - Rooholamini SA, Tebrani NS, Razari MK. Emerging of gallbladder carcinoma. Radiographics. 1994; 14: 291-306.

53 - De Arectxabala X, Riedman JP, Roa I, Wentzel C, Inostrosa J, Burgos L. Ca 19-9 and carnoembryonic antigen in gallbladder cancer. Rev. méd. Chile. 1996; 124: 11-20.

54 - Varshney S, Buttirini G, Gupta R. Incidental carcinoma of the gallbladder. Eur. j. surg. oncol. 2002; 28: 4-10.

55 - Muratore A, Polastri R, Capussotti L. Radical surgery for gallbladder cancer: current options. Eur. j. surg. oncol. 2000; 26: $438-43$.

56 - Collier NA, Blumgart LH. Tumores de la vesícula. In. Blumgart. Cirurgia del hígado y de las vias biliares. Buenos aires, Editorial Medica Panamericana S.A. 1998; v.2, p.954-66,

57 - Strasberg SM; Hertl M; Soper NJ. An analysis of problem injury during laparososcopic cholecystectomy. J. Am. Coll. Surg. 1995; 180: 638-9.

Recebido para publicação em 20/08/2008

Aprovado para publicação em 23/10/2008 